\title{
Liver Transplantation for Hepatocellular Carcinoma in the MELD Era: Leading Roles of MELD Score, AFP Level, and Recipient Age as Predictors of Survival
}

\author{
Georgios C. Sotiropoulos • Ernesto P. Molmenti • \\ Hauke Lang
}

Published online: 21 January 2009

(C) Springer Science+Business Media, LLC 2009

\section{Dear Editor,}

Adequate patient selection criteria and predictors of long-term survival are topics of major interest and discussion in liver transplantation (LT) for hepatocellular carcinoma (HCC). In a recent publication in Digestive Diseases and Sciences, in a study performed by our group on live-donor liver transplantation under a liberal HCC policy, sophisticated multivariable statistical analysis showed that while patient age $>60$ years and MELD $>22$ were negative predictors of short-term outcome, patient age $>60$ years and AFP $>400 \mathrm{ng} / \mathrm{ml}$ inversely correlated with long-term survival $[1,2]$. The above-mentioned cut-off values were statistically derived and not arbitrarily defined.

We were very excited to find out that almost the same predictors were defined by the largest contemporary series under a conservative HCC transplant policy, including 5,776 HCC transplant recipients [3]. Indeed, in a quasisimultaneous publication in Gastroenterology, Ioannou and co-workers reviewed the United Network for Organ Sharing (UNOS) database for LT performed between 1997 and 2007 and concluded that the adoption of MELD led to a 6fold increase in the transplantation of HCC patients [3]. They also observed that recipients with solitary HCC 3$5 \mathrm{~cm}$ in size, $\alpha$-fetoprotein (AFP) levels $\geq 455 \mathrm{ng} / \mathrm{ml}$ (hazard ratio, 2.15 ; 95\% CI: 1.5-2.0), MELD scores $\geq 20$ (hazard ratio, 1.61 ; 95\% CI: 1.3-2.1), age (hazard ratio,

G. C. Sotiropoulos $(\bowtie) \cdot$ H. Lang

Department of General and Abdominal Surgery, Johannes

Gutenberg University Hospital Mainz, Langenbeckstraße 1,

55131 Mainz, Germany

e-mail: sotiropoulos@ach.klinik.uni-mainz.de

E. P. Molmenti

Department of Surgery, North Shore University Hospital,

Manhasset, New York
1.32; $95 \%$ CI: $1.0-1.7$ for age $>61$ years), and AFP $\geq 455 \mathrm{ng} / \mathrm{ml}$ combined with MELD $\geq 20$ had a detrimental effect on survival [3].

The observation that MELD scores and AFP levels are predictors of survival is certainly of great clinical importance. Since age $>60$ years was also associated with diminished survival in the UNOS series, it would be interesting to have the risk of death in the UNOS recipients when combining AFP $\geq 455 \mathrm{ng} / \mathrm{ml}$, MELD $\geq 20$, and age $\geq 61$, which is unfortunately not provided. However, as it is clearly shown by these two contemporary and simultaneous studies, with liberal or conservative transplant HCC policy in Europe and USA, respectively, this new combination could prove to be an even better and applicable tool to evaluate patients with HCC and cirrhosis!

\section{References}

1. Sotiropoulos GC, Lang H, Sgourakis G, et al. Liberal policy in living donor liver transplantation for hepatocellular carcinoma: lessons learned. Dig Dis Sci. 2009; 54:377-384.

2. Popescu I. Living donor liver transplantation for hepatocellular carcinoma: defining criteria to extend indications. Dig Dis Sci. 2009; 54:199-200.

3. Ioannou GN, Perkins JD, Carithers RL Jr. Liver transplantation for hepatocellular carcinoma: impact of the MELD allocation system and predictors of survival. Gastroenterology. 2008;134:13421351. doi:10.1053/j.gastro.2008.02.013. 